\title{
Protocol for sterile conditions using dental photography
}

\author{
Radostina Vasileva ${ }^{1}$, Rossen Kolarov², Nikolay \\ Nikolov ${ }^{3}$
}

1. Department of Prosthetic Dentistry, Faculty of Dental Medicine, Medical University, Varna;

2. Department of Maxillo-oral Surgery, Faculty of Dental Medicine, Medical University, Varna;

3. Private dental practice - Plovdiv.

\begin{abstract}
In dental surgical procedures in outpatient practices and a lacking opportunity for video documentation, the operator or the assistant are needed to document with cameras the different stages in implantological or surgical dental treatment. A similar working protocol requires sterile conditions of photographic equipment and accessories for photographic documentation. The purpose of this article is to create and combine photographic and disinfection steps needed for a protocol of shooting during surgical treatment. The sterilization of such devices is not easy and is associated to certain difficulties. The use of specific combined protocols with sterile foil or autoclaved envelopes provide complete sterility and freedom in photographic and medical aspect.
\end{abstract}

Keywords: infection control, disinfection \& sterilization in dentistry; dental photography. 


\section{Introduction}

Dental photography, has imposed itself and has won wide popularity in the last decade. It can be applied in every dental specialty as a current and objective method of documentation and clinical analysis of the patient.

The popular use of dental photography concerns a number of issues related to the provision of good care to patients. The modern concepts related to patient care in dentistry are expected on the one hand to inform and on the other to eliminate the negative impact of possible infections.

A review of the available literature clarifies basic protocols of sterilization and disinfection in dentistry. Information is scarce if we look at the specific issue of photo documentation in sterile conditions, using SLRs in surgical interventions. Irfan Ahmad comments the issue in the accessible literature and suggests guidelines (1). The probability of harmful impact of infections in dental treatment is associated with the possible failure of the treatment, prolonging the healing process, possible relapse, additional treatment costs and patient's lowered satisfaction $(2,3)$.

These are the main reasons requiring dentists to take action aiming at the prevention of potential infections from photographic documentation.

The appearance of infections is a complex process that depends on many factors. Some of them are linked to the activity of the people providing the dental services, to the medical institution type, as well as to the specific conditions for sterilization of the used equipment (4).

Health services in Bulgaria and around the world unite measures and activities of regional hospitals and non-hospital / ambulatory surgical centers and practices $(5,6,7,8,9)$. This outlines the need for introducing recommendations for the sterile conditions of photographic documentation in dental surgery.

In dental surgical procedures in outpatient practices and with a lack of opportunity for video documentation, it is essential that the operator or the assistant documents different stages in implantological / surgical dental treatment. A similar protocol of work requires sterile conditions using equipment and accessories for photographic documentation.

The process of providing sterile conditions is based on the classic gold standard, "do not touch the sterile fields in photography." It is allowed for the operator to bend over the surgical field exclusively and only when authorized by a surgeon.

Undoubtedly, the best and most effective option for providing conditions for sterile photo and video documentation is the use of a camera or video camera set on a tripod and over the operator's head, which could be remotely controlled or operated on a continuous mode. Subsequently, it's possible to extract individual images and video from the videotape. Unfortunately, under the conditions set so, it is not possible to obtain good and creative shots, especially for the needs of dental photography.

The use of a camera and operator (medical photographer) is the best option for obtaining accurate and reliable photo materials of a surgical intervention. 
The camera, the lens and the flash cannot be sterilized easily. Only a part of the additional facilities, according to the manufacturer's instructions, can be subjected to autoclaving. The possibilities to ensure sterile conditions of photographic documentation in outpatient conditions are limited and with varying degrees of complexity and sterility.

Most cameras are made from plastic and rubber items that are porous, easily destructible and this in turn embarrasses the sterilization process.

Some cameras are made of metal alloys (aluminum and magnesium) with increased heat resistance, chemical irritants and other substances.

A camera with a possibility of an easy chemical sterilization is Shofu Eye Special C2. Apart from that and SLR cameras, this question has not been studied sufficiently.

\section{Objective:}

The purpose of this article is to create and combine photographic and disinfection steps necessary for a sterile protocol of photography in the surgical practice.

\section{Material and Methods:}

Disinfection is defined as destruction or irreversible inactivation of the germs in the external environment. Depending on the goals and the missions, the main methods of disinfection used in dentistry are: biological, mechanical, chemical and physical.

These mentioned options of disinfection in dental photography can be divided into the following groups: mechanical-chemical and physical-chemical. We consider that our proposal of combined steps will provide the necessary sterile conditions.

\section{Chemical disinfection and dental photography}

Alcohol-based disinfectants contain $70 \%$ ethanol, so the destruction of a spore-forming bacteria is not possible. Disinfectants containing methanol will be more effective, but there is a danger of distorting the camera`s plastic coating.

To facilitate photographing in surgical procedures, we provide an experimental photo-disinfection protocol with chemical disinfection, which we tested in outpatient conditions and we found its effectiveness after conducting microbiological analysis.

The protocol consists of two parts: photography and disinfection.

The photographic part is performed in non-sterile conditions, by aiming the full camera setting before surgical manipulation. All settings made at this stage are final and irreversible during the next sterile stage. 
The disinfection part aims to put the camera and the accessories in sterile conditions and give the opportunity to use them during the surgical manipulation.

Main stages of the experimental protocol with chemical disinfection:

Photographic part:

Used technical means: DSLR Canon 60D, macro lens Canon 100mm., ring flash. UV filter

- Using auto focus option.

- $\quad$ Selecting file formats (RAW \&JPEG).

- Reporting of exposure and framing through test shots before the sterilization, using the camera`s integrated light meter in programming mode $(P)$

- The camera is placed on priority aperture mode with aperture indications $f / 11$, ISO 200

- The flash is placed on the device and activates according to the corresponding modes

- Obligatory several test shots are done before proceeding to the second part of the protocol

Disinfection part:

- Preparation of the first sterile area (through a sterile cover) and the placement of the camera when not used.

- Preparation of the second sterile area with a sterile drape, where the disinfection of the camera is done precisely (the back, the handle body grip and shutter button of the DSLR camera are carefully disinfected) with a gauze moistened with disinfectant. Putting a protecting UV filter (application of disinfecting spray - a filter on the front lens of the objective-glass, application of the disinfecting spray on the plastic protector of the rings flash).

- The used disinfectant is Desident ${ }^{\mathrm{TM}}$ CaviCide with respected critical conditions (exposure 3 minutes and temperature $200 \mathrm{C}$ ).

- The camera is used with sterile gloves, without the lens and the flash

According to this protocol and following the necessary steps for the required conditions of sterility of photo documentation, we took swabs from disinfected surfaces before and after chemical disinfection.

To be objective in our study, we conducted different studies in two independent clinical laboratories: SMDL "City Lab" Varna. 
In support of these study, we provide some part of the microbiological results in a summarized table format /see tab.1/.

2. Mechanical sterile barrier:

Opportunities to create sterile conditions with a lens reflex camera: pack with sterile foil / surgical adhesive film, document with sterile gloves and create a mechanical sterile barrier. For the purpose of our study, we used Omnia Swiss Dent. Obligatory packing of the tripod and the flash. The disadvantage of this method is that the sterile foil could not be applied and used for the front lens. To provide precise conditions for sterility we combine the protocol with a chemically disinfected UV filter.

The best way to create sterile conditions is to autoclave the instruments. Thinking along these lines we suggest that the camera / the lens should be packed in an autoclaved envelope. The envelope is prepared and flared so as to provide an opening for the front lens. Again, the independent use of the method is insufficient and requires a combination with a chemical disinfection of the UV filter and mechanical or chemical disinfection of the flash adapter and the flash.

Photographic part:

DSLR Canon 60D macro lens Canon 100mm, ring flash, UV filter

- Using the auto focus option.

- Selecting file formats (RAW \& JPEG).

- Reporting of exposure and framing through test shots before the sterilization, using the camera`s integrated light meter in programming mode " $P$ ".

- The camera is placed on priority Aperture mode with $\mathrm{f} / 11$, ISO 200.

- The flash is placed on the device and activates according to the corresponding modes

- Obligatory several test shots are done before proceeding to the second part of the protocol.

Disinfection part:

- Chemical sterilization of the UV filter on previously prepared sterile area by disinfectant on the relevant exposure and temperature as proposed in our protocol

- Chemical disinfection of the camera and the flash according to our protocol suggestions 
- Preconditioning of the autoclave envelope and creating an opening for the front lens of the objective-glass

- Envelope autoclaving

- Placing the camera after its chemical disinfection in the autoclaved envelop wearing sterile gloves. Changing the gloves and sealing the front lens of the objective with chemical fumigated UV filter

\section{Results and discussion:}

In our opinion the achieved sterile conditions through chemical sterilization are good for surgery, but risky for the technology. This could lead to damage to the camera`s body in case of carelessness. The suggested protocol requires good technical knowledge and precision of the application, as otherwise it could lead to the damage of the technical equipment.

We provide the results from the microbiological laboratory SMDL City Lab Varna in Table 1. In this case the isolation of microorganisms on the back of the camera and insufficient reliability of the described protocol are established.

The results from the chemical disinfection we will provide in a summary table:

Table 1.

\begin{tabular}{|c|c|c|c|}
\hline $\begin{array}{l}\text { Canon EOS } 60 \text { D / } \\
\text { surfaces under } \\
\text { chemical sterilization }\end{array}$ & $\begin{array}{l}\text { Isolated microbial flora } \\
\text { before chemical } \\
\text { disinfection }\end{array}$ & $\begin{array}{l}\text { Isolated microbial flora } \\
\text { after chemical } \\
\text { disinfection }\end{array}$ & Lab study ID \\
\hline UV filter & $\begin{array}{l}\text { Enterobacter } \\
\text { aerogenes }>10^{5} \mathrm{CFU}\end{array}$ & $\begin{array}{l}\text { Without microbial flora } \\
\text { growth }\end{array}$ & $\begin{array}{l}573250 \\
573249 \\
\end{array}$ \\
\hline shutter button & $\begin{array}{l}\text { Enterobacter } \\
\text { aerogenes }>10{ }^{5} \mathrm{CFU}\end{array}$ & $\begin{array}{l}\text { Without microbial flora } \\
\text { growth }\end{array}$ & $\begin{array}{l}573252 \\
573262\end{array}$ \\
\hline handle / grip & $\begin{array}{l}\text { Staphilococcus } \\
\text { haemolyticus }>10^{5} \text { and } \\
\text { KOE Enterobacter } \\
\text { aerogenes }>10^{5} \mathrm{CFU}\end{array}$ & $\begin{array}{l}\text { Without microbial flora } \\
\text { growth }\end{array}$ & $\begin{array}{l}573253 \\
573265 \\
\end{array}$ \\
\hline back & $\begin{array}{l}\text { Staphilococcus } \\
\text { haemolyticus> } \\
10^{5} \mathrm{KOE} \quad \text { and } \\
\text { Enterobacter } \\
\text { aerogenes }>10^{2} \mathrm{CFU} \\
\end{array}$ & $\begin{array}{l}\text { Staphilococcus } \\
\text { haemolyticus }> \\
10^{2} \mathrm{KOE} \\
\end{array}$ & $\begin{array}{l}573254 \\
573257 \\
\end{array}$ \\
\hline $\begin{array}{l}\text { smart phone remote } \\
\text { control }\end{array}$ & $\begin{array}{l}\text { Staphilococcus } \\
\text { haemolyticus }> \\
10^{5} \mathrm{KOE}\end{array}$ & $\begin{array}{l}\text { Without microbial flora } \\
\text { growth }\end{array}$ & $\begin{array}{l}573255 \\
573251\end{array}$ \\
\hline
\end{tabular}


The protocol for sterile conditions with a sterile mechanical barrier is convenient and easy to implement. Through the film and the option for chemical disinfection damage to the underlying equipment can be avoided. The application of mechanical disinfection alone is insufficient. In our view, the combination with the chemical method for the UV filter disinfection for the front lens of the objective is right and appropriate. The advantage of this method is that it is the easiest possible way to manage the camera.

Sterile self-adhesive foils require additional cleaning of the expensive equipment and do not provide the necessary visibility. The discussed protocol is appropriate for dental photography with hard lens in order to eliminate possible violations of the mechanical barrier.

It`s proven that the best way for providing sterile conditions is autoclaving.

We use autoclaved sterile envelope with a pre-made hole on the front lens of the objective-glass. A previous setting of the camera is needed, but applied in this way the protocol for sterile documentation would preserve the equipment which is used to the greatest extent, and yet would ensure the sterility and the safety of the procedures while conducting the documentation. The method must utilize a chemically disinfected UV filter. (pict.1)
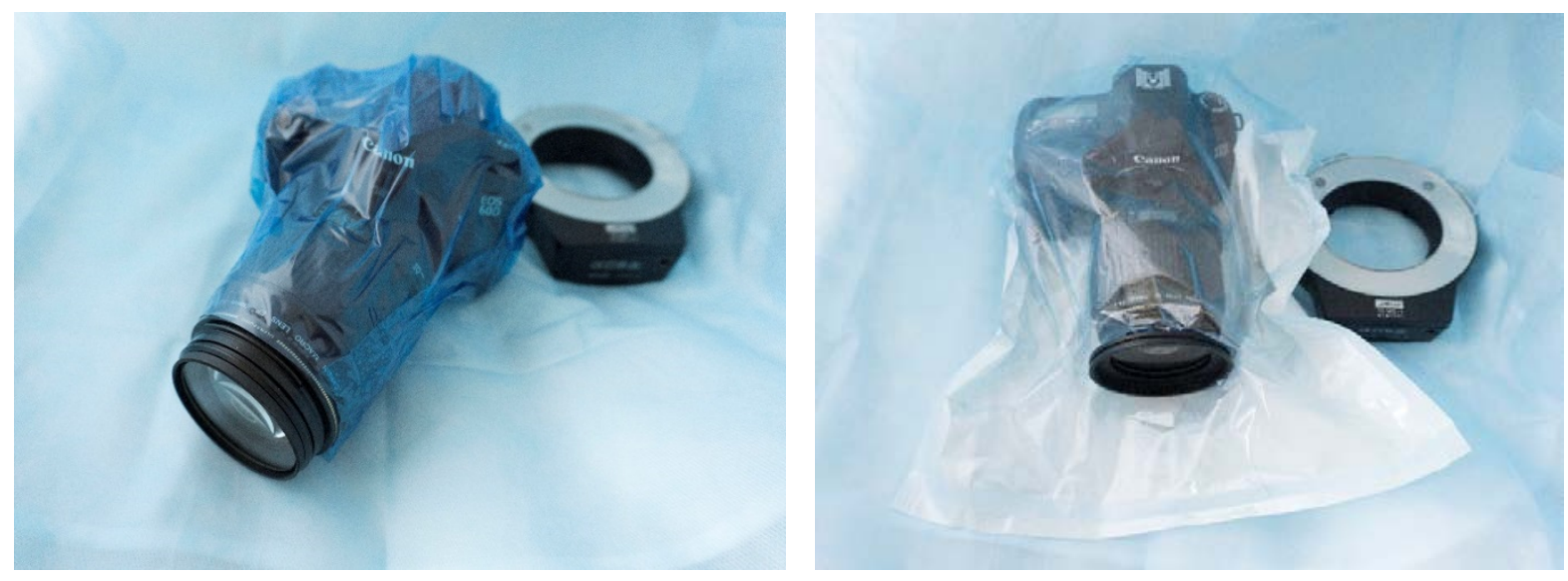

\section{Conclusion}

We believe that the steps we offer for sterile conditions of photo documentation must combine chemicalmechanical methods of disinfection and sterilization. In this way we will eliminate the possible risk of cross-contamination of the operative field while photo documenting and we will provide the best care for patients using dental photography. We believe that the protocol we offer addresses basic issues that have not been considered till this moment. 


\section{References}

1. Angelov L. Manual disinfection and sterilization in medical and dental practices; MES 2006.

2. Ahmad I. Digital dental photography. Part 4: choosing a camera. Br Dent J 2009 Jun 13;206 (11), 575-578.

3. Cannata S., Bek M., Baker P., et al. Infection control and contaminated waste disposal practices in Southern Sydney Area Health Service Dental Clinics. Aust Dent J 1997 Jun;42(3),199-202.

4. Contemporary Esthetic Dentistry: Sterilization and Disinfection. Chapter 32; 2012, 740-756.

5. Sterilization and disinfection of dental instruments by ADA, 2009.

6. Jakubovics N., Greenwood M., Meechan J.G. General medicine and surgery for dental practitioners: part 4. Infections and infection control. Br Dent J 2014 Jul; 217 (2), 73-77.

7. Gordon B.L., Burke F.J., Bagg J, et al. Systematic review of adherence to infection control guidelines in dentistry. J Dent 2001 Nov; 29 (8), 509-516.

8. Lakshya R., Pradeep Dr. Sterilization Protocols in Dentistry - A Review. J Pharm Sci \& Res. Vol. 8 (6), 2016, 558-564.

9. Wenzel A., Frandse E., Hintze H. Patient discomfort and cross-infection control in bitewing examination with a storage phosphor plate and a CCD-based sensor. Journal of Dentistry 1999, 27(3), 243-246.

\section{Corresponding author:}

Radostina Vasileva;

Faculty of Dental Medicine,

Medical University of Varna

55 Marin Drinov Str. 9002 Varna, Bulgaria

Tel.:0876744070 e-mail: radost11dent@abv.bg 